galiciens. Ces derniers ont su saisir toutes les opportunités offertes pour élargir leur espace de reconnaissance et donc d'intégration continentale.

La thèse défendue par l'auteur est que, au-delà des certaines similitudes sur les plans géographique, linguistique et culturel (comparaison en définitive à peine abordée), c'est l'usage politique qui détermine le mode d'appropriation des travaux ethnographiques. La question de l'autonomisation des savoirs est donc réduite à leur instrumentalisation d'ordre politique, faisant fi de leur contexte sociohistorique de production et du rôle légitimateur assigné, en dernière instance, non pas à l'ethnographie mais à l'histoire. En effet, en Galice les écrits ethnographiques, datant au plus d'environ un siècle, ont pour rôle d'authentifier les traditions culturelles, quitte à les réinventer. Or, c'est le passé du royaume de Galice au Moyen Âge qui légitime l'historicité du nationalisme face à la Couronne de Castille et en concurrence avec les spécificités historiques basques et catalanes.

On remarquera également que la Galice retient d'avantage l'attention du chercheur (sept chapitres sur dix), que la situation de l'aire portugaise du Minho dont la spécificité culturelle, qualifiée de «localiste», est diluée dans l'homogénéité de l'imaginaire national portugais. S'il s'agit là d'un souhait certain de l'État salazariste, il reste néanmoins en décalage avec les réalités des Açores ou de Madère qui ont elles-mêmes obtenu leur autonomie. La distinction théorique entre identité nationale et impériale est certes évoquée, mais la qualification des processus de construction de l'imaginaire collectif reste discutable. La première exposition coloniale portugaise de 1934, objet du chapitre VIII, « un exercice autoritaire de pédagogie impériale et nationaliste », affichait la volonté de consolider la nation dans sa diversité tout en imposant une vision centralisatrice qui subsumait les différences, nous dit Medeiros. Or, faut-il pour autant adhérer au postulat de l'efficacité dans la durée de cette représentation? En Espagne, pendant la dictature de Franco, qui, lui aussi, nourrissait des ambitions impérialistes, toute manifestation de velléité de différentiation identitaire a été réprimée ; cependant les aspirations autonomistes, portées par l'opposition au franquisme, lui ont survécu. Sous cet angle, la thèse de l'usage politique est insuffisante: les questions des finalités politiques et de l'adhésion à un imaginaire national donné mériteraient davantage d'être posées. Ainsi, l'affirmation du nationalisme galicien, né pendant les années de la República (1931-1936), est lisible à la lumière de la lutte antifranquiste, dont se revendique le Bloque Nacionalista Galego, front unitaire politiquement situé à gauche.

Très répétitif dans ses démonstrations et ses arguments, l'ouvrage est issu d'une thèse doctorale dont il a conservé de nombreux renvois bibliographiques dans le corps du texte et l'abondante bibliographie de vingt-trois pages. La conclusion, extrait anecdotique de notes de terrain, laisse le lecteur perplexe sur sa pertinence.

Mai 2008, Elisabetta Maino

Fátima Monteiro et al., Portugal. Strategic Options in a European Context, Lanham, Boulder - Nova Iorque, Oxford, Lexington Books, 2003, 222 p., ISBN : 0-73911-0509-4.

Este volume contém as comunicações apresentadas numa conferência no Minda de Gunzburg Center of European Studies, Universidade de Harvard, em Outubro de 
1999, com o patrocínio do então director do Centro, Charles Maier. Direccionado para um público de língua inglesa, iniciativas deste género devem ser devidamente louvadas, uma vez que permitem a um maior número de leitores acesso a informação sobre Portugal.

A introdução elaborada pelos editores define o objectivo da conferência como sendo o de dar, a investigadores da cultura, economia e ciência portuguesas, a oportunidade de avaliarem comparativamente o modo como Portugal e as suas instituições evoluíram durante os trezes anos da sua integração na União europeia. O conteúdo do volume foi organizado em quatro partes com os seguintes títulos: «Literatura e Identidade Nacional », «Economia e Finança, «Estado e Política Social, e «Ciência e Política de Investigação »; e, por sua vez, cada parte contém vários capítulos que variam em número. Pela estrutura física do livro, pode o leitor desde já avaliar que a sua organização não é homogénea, havendo muito mais peso na parte que contém os artigos sobre economia, política social e política da ciência e investigação. A qualidade dos artigos é também variável, sendo os da primeira parte no geral inferiores aos das restantes partes do livro.

No primeiro artigo dedicado à identidade nacional, foca-se o papel desempenhado pelos símbolos nacionais, entre os quais Camões e o seu poema épico Os Lusíadas tem lugar de destaque. Pensa-se que demasiado ênfase é dado ao uso que dele fez o Estado Novo, que, se bem o tenha utilizado como instrumento de propaganda colonialista, não impediu que nessa mesma data leitores inteligentes mais à esquerda politicamente, como por exemplo, António Sérgio, António José Saraiva, Jorge de Sena, fossem admiradores de Camões e usassem os seus textos de uma maneira totalmente diferente. É preciso não esquecer que Os Lusíadas, através dos tempos, ganharam na educação cívica portuguesa uma importância dominante, que fez do livro o breviário do patriotismo em momentos difíceis da nossa história. A revolução de 25 de Abril de 1974, ao pôr termo à censura, permitiu uma larga gama de experimentação literária como não se conhecera dantes. Daí que a leitura que Saramago fez de Os Lusíadas no seu livro O Ano da Morte de Ricardo Reis seja mais a sua própria interpretação da realidade encoberta pela retórica do estilo épico do que a representação das sensibilidades actuais portuguesas.

Outro artigo sobre a identidade nacional foca a popularidade do poeta Fernando Pessoa, cujo contraste com Camões não poderia ser maior. Curiosamente, enquanto este se tornou famoso por «cantar» os feitos dos portugueses, Pessoa ficou famoso pelo que não disse, ou melhor, pela crítica que dirigiu aos seus compatriotas. $\mathrm{Na}$ verdade, Pessoa, o ícone da cultura portuguesa do século xx não era realmente « um dos nossos », como muito bem o definiu Casais Monteiro, apelidando-o de « estrangeiro definitivo ».

Fecha esta primeira parte o artigo intitulado «A perda da Memória ». Embora muitas das asserções aí contidas sejam verdadeiras, haverá a dizer que especulações literárias sobre a identidade nacional podem ser enganadoras na medida em que representam apenas a opinião de uma pequena elite, enquanto que a maior parte dos portugueses se mantém indiferente. O conceito de identidade tem a sua utilidade, sempre e quando for usado com discrição e subtileza.

Em completo contraste, os artigos contidos nas outras três partes do volume focam assuntos de natureza económica, política e científica e cuja objectividade pode ser comprovada nas tabelas e gráficos incluídos, fornecendo ao leitor a mais 
recente informação sobre o progresso que se tem vindo a operar em Portugal desde a sua adesão à União europeia. Sendo um dos mais pequenos países da União, Portugal é um laboratório interessante para avaliar as consequências políticas e económicas da integração, as mudanças que se operaram, ao mesmo tempo que no capítulo que trata das finanças se esboçam aquelas que não estão ainda concretizadas. Entretanto, Portugal tem feito renovados esforços para acompanhar o desenvolvimento dos países do norte da Europa na área da providência social, se bem que em termos que são nitidamente portugueses. Até à data o país tem investido numa estratégia mais tradicional, mas a forma do modelo social português do futuro depende muito de como o problema do mercado de trabalho, dentro e fora do país, irá ser resolvido.

A tomada de consciência por sucessivos governos portugueses da necessidade de implementar programas na área da educação e da ciência e tecnologia levou finalmente ao financiamento de programas para preencher esta lacuna, usando contribuições substanciais da UE. Cabe aos futuros governos a responsabilidade de continuar a apoiar a educação, a ciência e a tecnologia, promovendo medidas e leis que se ajustem às novas realidades e desafios que se apresentam a Portugal. Finalmente, os artigos fornecem uma avaliação detalhada da emergência de Portugal na diplomacia e comércio internacionais, constituindo um modelo importante para estudos a serem efectuados num futuro próximo que avaliem o impacte que a integração na UE teve sobre a sociedade e a cultura dos novos países membros.

Maio de 2007, Carmo Ponte

\section{Gristina Udelsmann Rodrigues, « Os filhos não ligam. Os filhos não visitam ". O abandono dos idosos em São Tome e Príncipe, Lisbonne, s.e., 2004, 62 p., pas d'ISBN.}

Commandité par l'institution caritative portugaise Santa Casa da Misericórdia à l'occasion de la commémoration des 500 ans de son implantation à São Tomé e Príncipe (STP), cette publication révèle en soi au moins deux choses : l'une est la continuité des œuvres catholiques portugaises de bienfaisance dans cet archipel; l'autre, qui en découle, est la structuration de l'assistance publique sur des modèles surannés. C'est là un lourd héritage de cinq siècles de colonisation qui pourrait expliquer, du moins en partie, les déficiences post-indépendance en matière de politiques sociales...

Mais revenons plutôt à ce rapport de mission sur la situation des personnes âgées qui seraient, comme le titre l'annonce, abandonnés par les familles. Partant d'un constat général sur les changements en cours dans la pyramide des âges qui s'oriente vers le vieillissement de la population dans les pays développés, l'étude applique cette idée à l'Afrique, en dépit du fait que ce continent se caractérise plutôt par une situation inversée, car les jeunes de moins de 18 ans représentent plus de $50 \%$ de la population.

L'auteure reconnaît du reste que, à São Tomé e Príncipe, on n'enregistre point cette tendance au vieillissement, le taux des plus de 60 ans, environ $6 \%$, n'ayant pas subi de variations notables entre 1981 et 2001 (p. 18). Ainsi la question des idosos (vieux) ne se pose pas en termes démographiques, mais comme couche 